\title{
Outcome of Diode Laser Cyclophotocoagulation in Neovascular Glaucoma in Nigerians: A short-term follow-up
}

\author{
R Duke FWACS, U Asana FWACS, D Nkanga FWACS, FICS, A Ibanga FNMC \\ Department of Ophthalmology, College of Medical Sciences, University of Calabar, Calabar, Nigeria
}

\section{ABSTRACT}

Aim: To find out the short-term outcome of ciliary ablation with diode laser contact cyclophotocoagulation in Nigerians with neovascular glaucoma.

Methods: The study is a retrospective, non-comparative, interventional case series. Demographic data, ocular and systemic history were obtained. Clinical examination included visual acuity, intraocular pressure, number of intraocular pressure-lowering medications and type of treatment administered at the time of NVG diagnosis. Treatment with diode laser cyclophotocoagulation was instituted. Short-term outcomes were observed and patients were followed-up for three months.

Results: The study included 3 eyes of 3 patients; all above 40 years, 1 female and 2 male. At the time of NVG diagnosis, all three patients presented with severe ocular pain, and had VA between PL and NPL. Intraocular pressure on the average was $33 \mathrm{mmHg}$ at presentation, and associated with corneal oedema. At 3 months after initial diode laser photocoagulation (DLPC), the VA remained the same in all patients. No patient required repeat treatment. Pain reduction and lowering of the intraocular pressure were achieved at 3 months followup post-DLPC without anti-glaucoma medication. Conjunctival burns and chemosis were seen. All three eyes had corneal oedema and spontaneous hyphema by the $7^{\text {th }}$ day; with subsequent severe corneal blood stain.

Conclusions: Diode laser photocoagulation can be used as an acceptable non-invasive surgical intervention for the reduction of pain and lowering of intraocular pressure in Nigerians with neovascular glaucoma. Most shortterm complications are uneventful. The presence of hyphema with corneal oedema may enhance the occurrence of corneal blood stain in black people. The presence of corneal oedema may thus be a risk factor for corneal blood staining.

Key words: short-term outcome, diode laser, corneal staining

\section{INTRODUCTION}

Cyclophotocoagulation is a non-invasive surgical technique suggested in the management of neovascular glaucoma, after all modalities of medical and other surgical therapies have failed. ${ }^{1,2,3}$ Various lasers have been used for this procedure including, ruby, ND:YAG, argon, krypton and, more recently, trans scleral cyclophotocoagulation with the diode laser, which has been shown to be more effective with less side effects than the others. ${ }^{4,5}$ The diode laser, $810 \mathrm{~nm}$, has greater melanin absorption compared to other lasers. Of the various cyclodestructive laser procedures, the semi conductor diode system appears to posses the best combination of effectiveness, portability, expense, safety and ease of use. ${ }^{5,6}$

Three cases are described in this article to highlight the short-term results of treatment with diode laser contact cyclophotocoagulation (DLCP) in Nigerian patients with neovascular glaucoma. To the best of the authors' knowledge, there are no published short-term descriptions of the reaction of Nigerians with NVG to DLPC. Various theories have been described regarding the mechanism of cyclophotocoagulation. These include decreased aqueous production by destruction of ciliary blood vessels, coagulative necrosis, and destruction of the ciliary epithelium resulting in decreased aqueous production and increased aqueous outflow. Whatever the mechanism, the presence of ciliary body pigment is important in absorbing laser energy. Hyphema is commonly reported as one of the complications of DLPC. This report is perhaps the first to document corneal blood staining from the resultant hyphema.

\section{METHODS}

Three patients diagnosed with neovascular glaucoma were retrospectively reviewed from their case notes. All the patients had undergone a baseline systemic and ophthalmologic examinations, including visual acuity, IOP measurement, slit lamp biomicroscopic examination at presentation, before laser surgery, and at 1, 3, 6, and 12 months follow-up. Complications within the first three months up to the $12^{\text {th }}$ month were noted, and the number and types of medication were recorded.

\section{Procedure for DLPC}

DLPC was indicated for all three patients because their cases were considered to be ocular emergencies; the patients were

${ }^{*}$ Correspondence: Dr. Roseline Duke, Department of Ophthalmology College of Medical Sciences, University of Calabar, Cross Rivers State

- e-mail: dr.roselineduke@gmail.com 
in pain and had sustained elevated intraocular pressure in spite of anti-glaucoma medication. Two of the patients had no perception of light and needed urgent pain relief.

Success was defined as: final intraocular pressure between 9 and $21 \mathrm{mmHg}$, relief of pain, no signs of anterior segment inflammation, discontinuation of carbonic anhydrase inhibitor and no repeat procedure of DLPC. Short-term follow-up was defined as from onset of DLPC to the third month after surgery.

All patients were treated as out patients. Peribulbar anaesthesia was administered after cleaning with povidone $5 \%$. Patients were supine. The probe was placed $2.0 \mathrm{~mm}$ from the limbus. The power settings were placed at a start of 1.2 watts and progressively increased until the pop sound was heard. The power immediately below that at which the pop sound was heard was the chosen as the power for treatment. $360^{\circ}$ DLPC was performed on all eyes, however the number of burns varied. The power setting was $1.6 \mathrm{~W}$ in the first and third cases and $1.7 \mathrm{~W}$ in the second case, for a duration of 1.5 seconds. The number of shots administered was 30 in the second and third cases, while in the first it was 32 single shots and not continuous.

All the patients had the same immediate post-operative care. At the end of each procedure, an oral analgesic and anti inflammatory agents were prescribed for three days duration only. A topical antiglaucoma medication (Xalatan 0.001\%) was administered, and gradually tapered and discontinued when the DLPC appeared to have taken effect. A topical intensive steroid (Maxitrol) was utilized and gradually tapered when inflammation appeared to have subsided. Topical atropine $1 \%$ was also administered as well as a prophylactic topical antibiotic (Ciloxan 0.3\%) X4 daily.

\section{RESULTS}

Case 1

A 72-year-old woman presented with intense pain in the right eye of six months duration. She was a known hypertensive patient of 20 years duration and diabetes mellitus was confirmed 7 years earlier. In addition, she was diagnosed as having glaucoma about 8 months prior to the time of presenting at clinic. Ophthalmic examination revealed a visual acuity of NPL in the right eye and 6/24 in the left. Intraocular pressure on presentation was $54 \mathrm{mmh}$ and $24 \mathrm{mmhg}$ in the right and left eye respectively. The right eye revealed mild corneal oedema, a moderately shallow anterior chamber, iris new vessel and intumescent cataract. In the left eye, a nuclear cataract and early posterior subcapsular cataract were observed. Fundoscopy on the left eye revealed glaucomatous optic neuropathy and cup disc ratio of 0.8 . A diagnosis of right phacomorphic glaucoma, and neovascular glaucoma was made. Angle details showed a closed angle with a vascular membrane. The patient had right uneventful endocapsular cataract extraction as an emergency for phacogenic cataract. A week later, she had contact DLPC as detailed in table 1.

Table 1. Clinical Characteristics

\begin{tabular}{|c|c|c|c|c|c|c|}
\hline Character & \multicolumn{2}{|l|}{ Case 1} & \multicolumn{2}{|l|}{ Case 2} & \multicolumn{2}{|l|}{ Case 3} \\
\hline Age & \multicolumn{2}{|l|}{72} & \multicolumn{2}{|l|}{71} & \multicolumn{2}{|l|}{47} \\
\hline Sex & \multicolumn{2}{|l|}{$\mathrm{F}$} & \multicolumn{2}{|l|}{ M } & \multicolumn{2}{|l|}{ M } \\
\hline $\begin{array}{l}\text { Systemic } \\
\text { disease }\end{array}$ & \multicolumn{2}{|l|}{ Diabetis Mellitus } & \multicolumn{2}{|l|}{ Hypertension } & \multicolumn{2}{|l|}{ None } \\
\hline Systemic drugs & \multicolumn{2}{|c|}{ Stopped 2 years prior to presentation } & \multicolumn{2}{|l|}{ Calcium 2 blocker } & \multicolumn{2}{|l|}{ Nil } \\
\hline Ocular drugs & \multicolumn{2}{|l|}{ None } & \multicolumn{2}{|l|}{ None } & \multicolumn{2}{|c|}{$\begin{array}{l}\text { Abandoned medication \& refused } \\
\text { surgery }\end{array}$} \\
\hline Ocular & RE & LE & RE & LE & RE & LE \\
\hline Pain & Severe & Nil & Severe & Nil & Severe & Nil \\
\hline V A & NPL & $6 / 24$ & NPL & $6 / 24$ & PL & $3 / 60$ \\
\hline IOP & 54 & 24 & 37 & 18 & 42 & 28 \\
\hline Gonioscopy & $\begin{array}{l}\text { Closed angle, with } \\
\text { vascular membrane }\end{array}$ & Schaffer grd 3 & $\begin{array}{l}\text { Grade } 3 \\
\text { (closed)NVG }\end{array}$ & Schaffer 3 & $\begin{array}{l}\text { Closed angle, new } \\
\text { vessels }\end{array}$ & Shaffer grd 3 \\
\hline Cornea & Mild oedema & Clear & Mild Oedema & Clear & $\begin{array}{l}\text { Moderate } \\
\text { Oedema }\end{array}$ & \\
\hline Iris & Iris new vessel & Normal & iris new vessels & Normal & Iris new vessels & \\
\hline Lens & Intumescent lens & $\begin{array}{l}\text { Posterior } \\
\text { Subcapsular }\end{array}$ & Nuclear sclerosis & Nuclear sclerosis & Poor details & Clear \\
\hline Vitreous & haemorrhage & clear & $\begin{array}{l}\text { Vitreous } \\
\text { haemorrhage }\end{array}$ & Clear & clear & Clear \\
\hline Fundus & No RR & $\begin{array}{l}\text { Moderate non } \\
\text { proliferative DR \& } \\
\text { advanced } \\
\text { OAGlaucoma }(0.8)\end{array}$ & No RR & $\begin{array}{l}\text { Grade } 2 \\
\text { hypertensive } \\
\text { retinopathy } \\
\text { Normal disc }\end{array}$ & Poor RR & $\begin{array}{l}\text { End stage } \\
\text { Glaucomatous } \\
\text { optic atrophy } \\
\text { (CD 1.0) }\end{array}$ \\
\hline Diagnosis & $\begin{array}{l}\text { Rt Phacomorphic G } \\
\text { Neovascular Glauco } \\
\text { Lt Mild non Prolifer }\end{array}$ & $\begin{array}{l}\text { ucoma \& } \\
\text { a } \\
\text { ive DR \& OAG }\end{array}$ & $\begin{array}{l}\text { NVG } 2^{\circ} ? \text { Branch } \\
\text { Occlusion }\end{array}$ & tinal Vein & $\begin{array}{l}\text { Rt NVG } 2^{\circ} ? \mathrm{CRVC} \\
\text { Lt Advanced or Er }\end{array}$ & d stage Glaucoma \\
\hline
\end{tabular}


Case 2

A 71-year-old man was referred to the eye clinic from the hypertension clinic of the same institution on account of pain and loss of vision in the left eye for 2 months. Visual acuity was NPL in that eye. There was congestion, $5 \%$ hyphema and mild corneal oedema; however patient had iris new vessels and moderate nuclear sclerosis. There was vitreous haemorrhage with no red reflex or fundal details. Intraocular pressure was $37 \mathrm{mmhg}$. The right eye had a visual acuity of 6/24; anterior segment was normal except for moderate nuclear sclerosis. Fundoscopy revealed normal discs and Grade 2 hypertensive retinopathy. Emergency treatment was administered; with oral Diamox 500mg start and topical Xalatan $0.001 \%$. The patient had DLPC a week after presentation. Response is shown in tables 1 to 4 .
Case 3

A 47-year-old male glaucoma patient who had defaulted from the eye clinic 12 years before, presented with nausea and progressive pain in the right eye of 8 weeks duration. Examination revealed visual acuity of PL in the right eye. The eye was congested and there was corneal oedema. Twigs of new vessels were seen on the iris. The anterior chamber was deep. The lens was normal and clear, but there was a poor red reflex due to vitreous haemorrhage. Pressure was $42 \mathrm{mmhg}$ in that eye and 28 in the left. Visual acuity in the left eye was 3/60 with end stage glaucomatous atrophy and an open angle. Emergency ocular treatment was administered as in the previous cases. The patient had DLPC a week after diagnosis. Again response is presented in the tables.

Table 2. Ocular findings before and after diode laser contact cyclophotocoagulation

\begin{tabular}{|c|c|c|c|}
\hline Outcome measure & Case 1 & Case 2 & Case 3 \\
\hline VA & NPL & NPL & PL \\
\hline \multicolumn{4}{|l|}{ PAIN } \\
\hline Immediate preop & moderate & moderate & Moderate \\
\hline Day 1 Post op & moderate & moderate & Moderate \\
\hline 1 week Post op & Mild & Mild & Mild \\
\hline 1 month Post op & none & none & None \\
\hline 3 month & none & none & None \\
\hline \multicolumn{4}{|c|}{ ANTERIOR UVEITIS } \\
\hline Immediate preop & severe & severe & Severe \\
\hline Day 1 Post op & severe & severe & Severe \\
\hline 1 week Post op & moderate & moderate & Moderate \\
\hline 1 month Post op & mild & mild & Mild \\
\hline 3 month & none & none & None \\
\hline \multicolumn{4}{|c|}{ INTRAOCULAR PRESSURE } \\
\hline Immediate preop & $\begin{array}{l}32 \\
\text { NO Diamox } \\
\text { Timoptol } 0.5 \%\end{array}$ & $\begin{array}{l}28 \\
\text { Diamox } 250 \mathrm{mg} 6 \mathrm{hrly}+ \\
\text { Xalatan } 0.001 \%\end{array}$ & $\begin{array}{l}39 \\
\text { Diamox } 250 \mathrm{mg} 6 \mathrm{hrly}+ \\
\text { Xalatan } 0.001 \%\end{array}$ \\
\hline Day 1 Post op & $\begin{array}{l}31 \\
\text { NO Diamox } \\
\text { Timoptol } 0.5 \% \\
\text { Xalatan } 0.001 \%\end{array}$ & $\begin{array}{l}26 \\
\text { Diamox } 250 \mathrm{mg} 6 \mathrm{hrly}+ \\
\text { Xalatan } 0.001 \%\end{array}$ & $\begin{array}{l}32 \\
\text { Diamox } 250 \mathrm{mg} \text { 6hrly }+ \\
\text { Xalatan } 0.001 \%\end{array}$ \\
\hline 1 week Post op & $\begin{array}{l}28 \\
\text { NO Diamox } \\
\text { Timoptol } 0.5 \% \\
\text { Xalatan } 0.001 \%\end{array}$ & $\begin{array}{l}24 \\
\text { Diamox } 250 \mathrm{mg} \text { 6hrly }+ \\
\text { Xalatan } 0.001 \%\end{array}$ & $\begin{array}{l}34 \\
\text { Diamox } 250 \mathrm{mg} \text { 6hrly }+ \\
\text { Xalatan } 0.001 \%\end{array}$ \\
\hline 1 month Post op & $\begin{array}{l}18 \\
+\quad \text { Xalatan } 0.001 \%\end{array}$ & $\begin{array}{l}12 \\
+ \text { Xalatan } 0.001 \%\end{array}$ & $\begin{array}{l}11 \\
+\quad \text { Xalatan } 0.001 \%\end{array}$ \\
\hline 3 month & 12 & 10 & 9 \\
\hline \multicolumn{4}{|l|}{ HYPHEMA } \\
\hline Immediate preop & Absent & $<5 \%$ & Absent \\
\hline Day 1 Post op & Absent & $<5 \%$ & Absent \\
\hline 1 week Post op & $25 \%$ & $40 \%$ & $15 \%$ \\
\hline 1 month Post op & No further view & No further view & No further view \\
\hline 3 month & No further view & No further view & No further view \\
\hline \multicolumn{4}{|c|}{ CORNEAL OEDEMA } \\
\hline Immediate preop & mild & Mild & Moderate \\
\hline Day 1 Post op & mild & Mild & Severe \\
\hline 1 week Post op & moderate & Moderate & Moderate \\
\hline 1 month Post op & mild & Mild & Mild \\
\hline 3 month & nil & Nil & Nil \\
\hline \multicolumn{4}{|c|}{ CORNEAL BLOOD STAIN } \\
\hline Immediate preop & Absent & Absent & Absent \\
\hline Day 1 Post op & Absent & Absent & Absent \\
\hline 1 week Post op & Early corneal blood satin & Early corneal blood stain & Early corneal blood stain \\
\hline 1 month Post op & Dense corneal blood stain & Dense corneal blood stain & Dense corneal blood stain \\
\hline 3 month & Same & Same & Same \\
\hline
\end{tabular}




\section{DISCUSSION}

Neovascular glaucoma is not uncommon. It is a severe type of secondary angle closure glaucoma caused by various disorders and characterized by retinal ischaemia or ocular inflammation. It is also common in poorly controlled advanced chronic simple glaucoma. The visual prognosis for NVG is usually poor. ${ }^{7}$ Medical therapy is often not effective in controlling IOP when the outflow system has been occluded. ${ }^{8,9}$ Filtration is usually only successful when neovascularization has regressed after panretinal photocoagulation and a better outcome with the use of antimetabolites. Tube shunt surgery has also been found to be effective in reducing IOP. However, if these fail, a cyclodestructive procedure may be necessary to reduce IOP. The treatment of choice when the ocular media are clear is panretinal photocoagulation in the first instance, and more recently, intravitreal Avastin, irrespective of media clarity. ${ }^{3,8}$ In this series, none of the patients presented with a clear ocular media, and all presented late, at least six weeks from onset of pain. When a cloudy media prevents retinal laser therapy, conservative and symptomatic treatment becomes the option. DLPC has been identified as an efficient treatment for neovascular glaucoma., ${ }^{2,5,8,10}$

Cyclophotocoagulation is indicated for: patients with refractory glaucoma for whom trabeculectomy or tube shunt procedures have failed; patients with minimal useful vision and elevated intraocular pressure; and patients who have no visual potential and need pain relief. ${ }^{6}$ The patients in this series fit into at least two of these categories. However, for NVG in these patients, uncontrolled pain was the priority indication for treatment. The use of diode laser cyclophotocoagulation has been associated with variability in laser parameters. ${ }^{11}$ The higher the power, the more effective the therapy with DLPC. ${ }^{11,12}$ The average is between 1.6 and $3 \mathrm{~mW}$. The power used in this study was in the range of $1.6-1.7 \mathrm{~W}$. The probability of success is increased significantly with age, for patients older than 50 years. ${ }^{13}$ Two of our patients were above 50 years, however, previous ocular surgery decreased the success probability. This was not the case in the diabetic who had cataract extraction prior to DLPC.

Relief of pain occurred in all three patients without systemic analgesia by the first week. This result is similar to that of another study. ${ }^{13}$

Visual acuity remained the same in the only eye with perception of light. Visual loss from perception of light to no perception of light has been seen in other studies, ${ }^{9,10,14}$ however, this difference in results may be due to the fact that our study population is small.

DLPC may be an unpredictable procedure due to variability in the surgeon's delivery method, and variability in pressure exerted over the sclera. Difference in scleral pressure in patients may also contribute to this variability but certain short-term complications of DLPC treatment may be predictable. The use of DLPC in the treatment of NVG has been shown to lower intraocular pressure and reduce ocular pain regardless of its complications, as was seen in this study. Furthermore, two out of the patients developed persistently low intraocular pressure (less than $10 \mathrm{mmh}$ ), after the third month.

Anterior segment inflammation, conjunctival oedema, conjunctival congestion and conjunctival burns were noted as early and short-term complications. This is similar to the results in an earlier report. ${ }^{4}$ Anterior segment and conjunctival inflammation subsided in all three cases by the third month of follow-up. Conjunctival burns healed within a week after surgery. Second or repeat treatment has been carried out within six weeks of surgery, but this was not necessary within the period of one to three months after the initial treatment. ${ }^{1,8,14}$

Hyphema is a known complication of DLPC. This has been documented to be a common side effect in patients with $\mathrm{NVG}^{8,11}$ when compared with some studies on POAG, in which it is said to be transient and not frequent. A comparative study of NVG and POAG, however, did not show any difference in the rate of hyphema. ${ }^{10}$ The incidence rate of transient hyphema in the anterior chamber and of transient exudate in the anterior chamber of patients with NVG were significantly higher, with an energy per pulse of $2.5 \mathrm{~W}$ in 2 seconds compared to $2.0 \mathrm{~W}$ in 1.5 seconds. ${ }^{11}$ This is higher than the energy pulse utilized in this report which was between 1.6-1.7W. The presence of ciliary body pigment is important in absorbing laser energy. This contributes to the need and effect of different energy pulse in people from different racial backgrounds. The three patients discussed were Nigerians.

Corneal blood stain has not been documented in the use of DLPC to treat NVG. Hyphema in the presence of corneal endothelial compromise, and eventually corneal decompensation, irrespective of the intraocular pressure, results in corneal blood staining. In these three patients, corneal blood staining was seen a week following hyphema in the presence of corneal oedema; this, following a single treatment with DLPC. This appears to be the most significant short-term complication following DLPC treatment in this group of patients. Anterior chamber paracentesis may be indicated in such patients; however the patients in this review refused surgery. Corneal blood staining was not an acceptable cosmetic occurrence. While the pain was no longer a problem to all three patients by the third month of review, they all complained about the 'dark colouring' in the eye. They found it undesirable but, in comparison to the pain, were glad for the treatment. Patients should be warned that corneal blood staining may occur within the first week in NVG following the use of DLPC in Nigerian patients.

\section{CONCLUSION}

A short-term review of three cases of NVG in Nigerians treated with DLPC showed that even though the procedure is easy to perform, effective in lowering IOP, and is a safe and less time-consuming method for pain relief and lowering IOP, corneal blood staining may develop following 
hyphema and corneal decompensation. A prospective study using a larger sample size for the treatment parameters may establish corneal oedema as a risk factor for corneal blood staining. Furthermore, physicians should be cautious about DLPC treatment of neovascular glaucoma associated with corneal oedema.

\section{REFERENCES}

1. Frezzotti P, Mittica V, Martone G, Motolese I, Lomurno L, Peruzzi S, Motolese E. Longterm follow-up of diode laser transscleral cyclophotocoagulation in the treatment of refractory glaucoma. Acta Ophthalmol 2009; 88(1): 150-5.

2. Sivak-Callcott JA, O'Day DM, Gass JD, Tsai JC. Evidence based recommendations for the diagnosis and treatment of neovascular glaucoma. Ophthalmology 2001; 108:17671776.

3. Iliev ME, Domig D, Wolf-Schnurrbursch U, Wolf S, Sarra GM. Intravitreal Bevacizumab in the treatment of neovascular glaucoma. Am J Ophthalmol 2006; 142: 10541056.

4. Ada, Subrata Mandal et al. Update on cyclophotocoagulation. Dheli J Ophthalmol 2007; 12: 61-72.

5. Oguri A, Takahashi E, Tomita G, Yamamoto T, Jikihara S, Kitazawa Y. Transscleral cyclophotocoagulation with the diode laser for neovascular glaucoma. Ophthalmic Surg Lasers. 1998;29(9): 722-7.

6. Pastor SA, Singh K, Lee DA, Juzych MS, Lin SC, Netland PA, Nguyen NT. Cyclophotocoagulation: a report by the American Academy of Ophthalmology. Ophthal 2001; 108(11): 2130-8.

7. Heuer DK, Lloyd MA. Management of glaucomas with poor surgical prognosis. Focal points: Clinical Modules for Ophthalmologists. San Francisco: American Academy of Ophthalmology; 1995, module1.
8. Leszcynski R, Domanski R, Forminska-Kapuscik M, Mrukwa-Kominek E, Rokita-Wala I. Contact transcleral cyclophotocoagulation in the treatment of neovascular glaucoma: a five-year follow up. Med Sci Monit 2009; 15(3): BR84-7.

9. Kosoko O, Gaasterland DE, Pollack IP, Enger CL. Longterm outcome of initial ciliary ablation with contact diode laser transscleral cyclophotocoagulation for severe glaucoma. The Diode Laser Ciliary Ablation Study Group. Ophthalmology 1996; 103(8): 1294-302.

10. Pokroy R, Greenwald Y, Pollack A, Bukelman A, Zalish M. Visual loss after transscleral diode laser cyclophotocoagulation for primary open-angle and neovascular glaucoma. Ophthalmic Surg Lasers Imaging 2008; 39(1): 22-9.

11. Chang SH, Chen YC, Li CY, Wu SC. Contact diode laser transscleral cyclophotocoagulation for refractory glaucoma: comparison of two treatment protocols. Can J Ophthalmol 2004; 39(5): 511-6.

12. Hauber FA, Scherer WJ. Influence of total energy delivery on success rate after contact diode laser transscleral cyclophotocoagulation: a retrospective case review and meta-analysis. J Glaucoma 2002; 11(4): 329-33.

13. Schlote T, Derse M, Rassmann K, Nicaeus T, Dietz K, Thiel HJ. Efficacy and safety of contact transscleral diode laser cyclophotocoagulation for advanced glaucoma. J Glaucoma 2001; 10(4): 294-301.

14. Gupta V, Agarwal HC. Contact trans-scleral diode laser cyclophotocoagulation treatment for refractory glaucomas in the Indian population. Indian J Ophthalmol 2000; 48(4): 295-300. 